\title{
Bax inhibitor-1 suppresses early brain injury following experimental subarachnoid hemorrhage in rats
}

\author{
JIAXIN LIU ${ }^{1-3}$, SHUAI ZHOU ${ }^{2,3}$, YUETING ZHANG ${ }^{4}$, XIUYING $\mathrm{LI}^{3}$, \\ XIYING QIAN $^{2}$, WEIHUA TAO ${ }^{2}$, LIDE JIN $^{2}$ and JIANHUA ZHAO ${ }^{2}$
}

\begin{abstract}
${ }^{1}$ Department of Environmental Science, Faculty of Environmental Science and Engineering, Kunming University of Science and Technology, Kunming, Yunnan $650504 ;{ }^{2}$ Department of Neurosurgery, The First Affiliated Hospital of Kunming University of Science and Technology, Kunming, Yunnan 650032; ${ }^{3}$ Department of Pharmacology, Medical School, Kunming University of Science and Technology, Kunming, Yunnan 650504; ${ }^{4}$ Very Important Person Ward, The Second Affiliated Hospital of Kunming Medical College. Kunming, Yunnan 650032, P.R. China
\end{abstract}

Received February 15, 2018; Accepted September 4, 2018

DOI: $10.3892 /$ ijmm.2018.3858

\begin{abstract}
Early brain injury (EBI) following subarachnoid hemorrhage (SAH) is an important cause of high mortality and poor prognosis in SAH. B-cell lymphoma 2-associated X protein inhibitor-1 (BI-1) is an evolutionarily conserved antiapoptotic protein that is primarily located in the membranes of endoplasmic reticulum (ER). BI-1 has been studied in certain nervous system-associated diseases, but the role of this protein in SAH remains unclear. In the present study, the role of BI-1 in EBI following SAH was investigated in rat models and its associated mechanisms were examined. The SAH rat model was generated by inserting nylon cords into the internal carotid artery from the external carotid artery. Samples were assessed using neurological scores, brain water content measurements, hematoxylin and eosin (H\&E) staining, blood-brain barrier (BBB) permeability, terminal deoxynucleotidyl transferase-mediated dUTP nick-end labeling and quantitative polymerase chain reaction assays, and western blot analyses. It was identified that the mRNA
\end{abstract}

Correspondence to: Professor Jianhua Zhao, Department of Neurosurgery, The First Affiliated Hospital of Kunming University of Science and Technology, 157 Jinbi Road, Kunming, Yunnan 650032, P.R. China

E-mail: zjh391km@163.com

Abbreviations: $\mathrm{SAH}$, subarachnoid hemorrhage; EBI, early brain injury; BI-1, B-cell lymphoma 2-associated X protein-inhibitor-1; $\mathrm{ER}$, endoplasmic reticulum; qPCR, quantitative polymerase chain reaction; $\mathrm{BBB}$, blood-brain barrier; $\mathrm{H} \& \mathrm{E}$, hematoxylin and eosin; TUNEL, terminal deoxynucleotidyl transferase-mediated dUTP nick-end labeling

Key words: B-cell lymphoma 2-associated X protein-inhibitor-1, early brain injury, subarachnoid hemorrhage, endoplasmic reticulum stress, apoptosis and protein levels of BI-1 decreased markedly and were lowest at $24 \mathrm{~h}$ after SAH. BI-1 overexpression and small hairpin RNA (shRNA)-mediated silencing markedly suppressed or severely exacerbated EBI following SAH, respectively. BI-1 overexpression in the SAH model improved neurological scores and decreased the brain water content, BBB permeability and levels of apoptosis compared with the control and sham groups following SAH. BI-1 shRNA in the SAH model demonstrated contrary results. In addition, the mRNA or protein expression levels of ER stress-associated genes (glucose regulated protein, $78 \mathrm{kDa}, \mathrm{C} / \mathrm{EBP}$ homologous protein, Serine/threonine-protein kinase/endoribonuclease IRE1, c-Jun $\mathrm{N}$ terminal kinases and apoptotic signaling kinase-1) were markedly suppressed or increased following BI-1 overexpression and shRNA-mediated silencing, respectively. The present study suggested that BI-1 serves a neuroprotective role in EBI following SAH by attenuating BBB disruption, brain edema and apoptosis mediated by ER stress.

\section{Introduction}

Subarachnoid hemorrhage (SAH) is one of the most common cerebrovascular events, with high rates of mortality and disability (1). SAH may occur at different ages, ranging from children to the elderly, and the incidence gradually increases with age. Although drugs and surgical technologies are being continuously developed, the mortality rate remains as high as $30-50 \%$, and the prognosis of patients with SAH is poor (1).

Early brain injury (EBI) refers to direct injury to the whole brain within the initial $72 \mathrm{~h}$ after SAH. EBI is a complicated event that is the result of normal brain physiological disorder, which may lead to early brain edema, oxidative stress, apoptosis and cerebral infarction, and may subsequently lead to mortality or severe disability $(2,3)$. The term EBI has been adopted and describes an immediate injury to the brain following SAH prior to the onset of delayed vasospasm (4). During the EBI period, a ruptured aneurysm causes a number 
of physiological disruptions, including increased intracranial pressure (ICP), decreased cerebral blood flow (CBF), and global cerebral ischemia. These events initiate secondary injuries including blood-brain barrier disruption, inflammation and oxidative cascades that all ultimately lead to cell death (4). Therefore, studies on EBI have substantial potential value in the treatment and prognosis of patients with SAH. At present, a number of studies have identified that early brain injury may be a primary factor of poor prognosis of SAH $(2,3,5)$. SAH may lead to neuronal cell apoptosis, and apoptosis primarily occurs in neurons of the hippocampus and basal cortex $(6,7)$. SAH also disrupts the blood-brain barrier (BBB) and increases permeability $(4,5)$. Cerebral edema is a direct result of $\mathrm{BBB}$ destruction. It has been suggested that a number of signal pathways serve important roles in EBI following SAH. The phosphoinositide 3-kinase (PI3K)/protein kinase B (Akt) pathway, a key antiapoptotic signaling pathway associated with EBI following SAH (8-10), and the c-Jun N-terminal kinase (JNK) associated signal pathway have been studied in EBI (7).

B-cell lymphoma 2 (Bcl-2)-associated X protein (Bax) inhibitor-1 (BI-1), also known as TMBIM6, was first identified by exploiting the lethal phenotype of Bax in yeast (11). BI-1 is an evolutionarily conserved endoplasmic reticulum (ER) protein that suppresses cell death in animal and plant cells (12). Numerous studies have suggested a role of ER stress in neuronal cell death $(13,14)$.

BI-1 has an association with ER, and it may also suppress the apoptosis induced by Bax. It has been demonstrated that ER is involved in the apoptosis induced by unfolded protein responses (UPRs) (15). Among the UPRs, inositol-requiring enzymes (IRE) are associated with cell death (14). Serine/threonine-protein kinase/endoribonuclease IRE1 (IRE1) is an important factor in the ER-targeted activities of Bcl-2-family proteins (16). Glucose regulated protein, $78 \mathrm{kDa}$ (GRP78) may regulate ER function during ER stress (17). IRE1 may activate downstream protein kinases, particularly apoptotic signaling kinase-1 (ASK1), which may cause JNK activation (18). IRE may also activate p38 mitogen activated protein kinase (MAPK), which activates the transcriptional regulator $\mathrm{C} / \mathrm{EBP}$ homologous protein $(\mathrm{CHOP})$ that controls the expression of numerous apoptotic genes (19). The cytoprotective activity of BI-1 is closely associated with ER stress $(20,21)$.

The function of BI-1 has been studied in a number of pathological models, including non-small cell lung cancer (22), prostate cancer (23), liver regeneration (24), ischemia (21) and diabetes (25). It has been demonstrated that BI-1 protects against stroke and traumatic brain injury (20). Bax inhibitor-1 may improve survival and neuronal differentiation of embryonic stem cells via the differential regulation of MAPK activities (26). BI-1 overexpression in the ER is protective in neurons (27). It has been suggested that the expression of BI-1 may be regarded as a novel therapy for brain-associated diseases. However, studies concerning the association between BI-1 and SAH have rarely been performed.

The present study investigated whether BI-1 protected the brain against EBI following SAH in rats. In addition, the role of ER stress-mediated apoptosis in SAH rat models was discussed.

\section{Materials and methods}

Ethics statement and animals. Seventy healthy male Sprague-Dawley rats (7-week old), weighing 180-200 g, were purchased from the Experimental Animal Center of Kunming Medical University (certificate no. SCXK2005-0008). The animal experiments were approved by the Animals Ethics Committee of Kunming Medical University and the Guide for the Care and Use of Laboratory Animals. All rats were housed in a humidity-controlled (50-65\%) pathogen-free environment with ad libitum access to food and water under 12/12 h light: Dark cycle $\left(18-22^{\circ} \mathrm{C}\right)$.

Plasmids. The rat BI-1 sequence was obtained from NCBI (https://www.ncbi.nlm.nih.gov/nuccore/NM_019381.2), and inserted into the pCDH plasmid (System Biosciences, LLC, Palo Alto, CA, USA) with EcoRI and NotI enzyme sites. The short hairpin RNA (shRNA) sequence for BI-1 was 5'-GCA CCTAAAGAAGGTCTATGC-3' (Sangon Biotech Co., Ltd., Shanghai, China). The BI-1 oligos (forward, 5'-CCGGGCACC TAAAGAAGGTCTATGCCTCGAGGCATAGACCTTCTT TAGGTGCTTTTTG-3' and reverse, 5'-AATTCAAAAAGC ACCTAAAGAAGGTCTATGCCTCGAGGCATAGACCTT CTTTAGGTGC-3') (Sangon Biotech Co., Ltd.) were annealed and inserted into the pLKO.1 plasmid (Addgene, Inc., Cambridge, MA, USA) with EcoRI and AgeI enzyme sites. The shRNA sequence for scrambled shRNA/pLKO.1 (Addgene, Inc.) was 5'-CCTAAGGTTAAGTCGCCCTCG-3'. These plasmids were sequenced by Sangon Biotech Co., Ltd. Furthermore, the efficiency of plasmids was verified by quantitative polymerase chain reaction (qPCR) and western blot analysis according to the following protocol. The sequence of rat BI-1 as follows: 5'-ATGAATATATTTGATCGGAAGATC AACTTTGATGCCCTCTTAAAATTTTCCCACATAACT CCCTCCACACAGCAGCACCTAAAGAAGGTCTATGCC AGTTTTGCACTGTGCATGTTTGTGGCAGCAGCAGGG GCCTATGTCCATGTGGTCACACGTTTCATCCAGGCT GGCCTGCTCTCTGCCCTGGGCGCCCTGGCCTTGATG ATTTGCCTGATGGCCACACCTCACAGCCATGAGACG GAGCAGAAGAGGCTGGGACTGCTCGCTGGCTTCGCC TTCCTTACAGGAGTTGGCCTGGGACCTGCCCTGGAG CTGTGCATTGCCATCAACCCCAGCATCCTCCCCACG GCCTTCATGGGCACGGCCATGATCTTCACCTGCTTC AGCCTGAGTGCCCTCTACGCCAGGCGCCGGAGTTAC CTCTTTTTGGGAGGTATCTTGATGTCAGCCATGAGC CTCATGTTCGTGTCCTCTCTGGGGAACCTTTTCTTT GGATCCATTTGGCTGTTCCAGGCAAACCTGTACATG GGGCTGCTGGTCATGTGCGGCTTTGTCCTCTTCGAC ACTCAGCTCATTATTGAAAAGGCTGAACACGGAGAC AAGGATTACATCTGGCACTGCATTGACCTCTTCTTG GACTTCGTTACACTCTTCAGGAAGCTCATGCTGATC TTGGCCTTCAATGAGAAGGACAAAAAGAAAGAGAA GAAGTGA-3'.

Transfection. The following groups were designed: NC group (transfection reagent), pCDH group, BI-1/pCDH, BI-1/pLKO.1 shRNA and scrambled shRNA/pLKO.1. The aforementioned plasmids were transfected with Lipo8000 ${ }^{\mathrm{TM}}$ Transfection Reagent (Beyotime Institute of Biotechnology, Haimen, China) into rat normal neuron cells (Chi Scientific, Inc., Maynard, 
MA, China), respectively. A total of $48 \mathrm{~h}$ after transfection, all transfected cells were collected for qPCR and western blot analysis, according to the following protocol.

SAH model and transfection. The rats were randomly divided into the following five groups $(n=8)$ : Control; sham; SAH $24 \mathrm{~h}$; SAH $48 \mathrm{~h}$; and SAH $72 \mathrm{~h}$ groups. The SAH model was induced in rats via puncture of the internal carotid artery. The SAH rat model was generated according to a protocol outlined by Prunell et al (28). Briefly, the rats were anesthetized with sodium pentobarbital $[30 \mathrm{mg} / \mathrm{kg}$ body weight, intraperitoneal injection (i.p)]. Then, the right carotid artery branch was exposed, and the external carotid artery (ECA) was blocked by vascular clamp. The ECA was cut at the proximal end of the vascular clamp, a nylon cord was inserted into the internal carotid artery from the ECA and then moved forward $3 \mathrm{~mm}$ when resistance was felt. Subsequently, the nylon cord was quickly removed. In total, the entire procedure lasted $<30 \mathrm{sec}$. The rats in the sham group only had the right carotid artery branch exposed, without any surgery, and rats in the control group had not undergone any surgical procedures. Rats were euthanized with sodium pentobarbital overdose (150 mg/kg i.p.). All of the aforementioned rats were assessed for behavioral scores as described subsequently to determine neurological impairment, then half of the brain samples were collected subsequent to being perfused with PBS and fixed at room temperature for one day in $4 \%$ paraformaldehyde for $\mathrm{H} \& \mathrm{E}$ staining, immunohistochemistry, terminal deoxynucleotidyl transferase-mediated dUTP nick-end labeling (TUNEL) staining and BBB injury assessment. The other half of the brain samples were stored in liquid nitrogen for $\mathrm{qPCR}$ and western blot assays as described subsequently.

In the second part of the experiments, rats were randomly divided into the following five groups $(n=6)$ : The sham; $\mathrm{SAH}$; $\mathrm{SAH}+\mathrm{NC}(\mathrm{SAH}+$ transfection reagent); SAH+BI-1 overexpression (SAH+BI-1 over); and SAH+BI-1 shRNA groups. The BI-1/pCDH overexpression and BI-1/pLKO.1 shRNA plasmid were transfected with Entranster-in vivo DNA transfection reagent (Engreen Biosystem NZ, Ltd., Auckland, New Zealand) by using a ventricular puncture stereotactic apparatus and a microinjection pump. Briefly, $5 \mu \mathrm{g}$ plasmids were dissolved in $5 \mu \mathrm{l}$ sterile water, and $10 \mu \mathrm{l}$ Entranster-in vivo DNA transfection reagent was added to $5 \mu \mathrm{l}$ plasmid. Then, the mixture was incubated for $15 \mathrm{~min}$ at room temperature. Finally, the aforementioned mixture was injected by using a microinjection pump under a ventricular puncture stereotactic apparatus. The SAH model was constructed $24 \mathrm{~h}$ after this process. All of the rats were assessed for behavioral scores as described subsequently to determine neurological impairment, and all samples were collected as aforementioned.

Neurological impairment. The neurological deficits were scored blindly to assess behavioral performance following ischemic injury according to the method outlined by Sugawara et al (29). This method was divided into six parts, namely: Autonomic activity; limb movement; forelimb extension; self-climbing cage; axillary touch response; and nasal hair touch response. Each category was scored out of 3 points, with a total of 18 points available. The evaluation process lasted $\sim 5 \mathrm{~min}$.
Brain edema. Brain edema was examined by using the wet-dry method: The rats were euthanized with sodium pentobarbital (150 mg/kg i.p.). The whole brain tissues were collected and weighed immediately, the measurement of which was considered the wet weight. Then, brain tissues were placed into the oven at $100^{\circ} \mathrm{C}$ for $72 \mathrm{~h}$ and then weighed, and this was considered dry weight. The brain edema index (\%) was calculated as follows: [(Wet weight-dry weight)/wet weight] x100\%.

Hematoxylin and eosin $(H \& E)$ staining. Fixed brain tissues were dehydrated with various concentrations of xylene and ethanol $(50 \%$ ethanol for $4 \mathrm{~h}, 75 \%$ ethanol for $4 \mathrm{~h}, 85 \%$ ethanol for $3 \mathrm{~h}, 95 \%$ ethanol for $2 \mathrm{~h}, 100 \%$ ethanol for $1 \mathrm{~h}, 100 \%$ ethanol for $1 \mathrm{~h}, 1: 1$ ethanol-xylene for $1 \mathrm{~h}$, xylene for $1 \mathrm{~h}$ and xylene for $30 \mathrm{~min}$ at room temperature), embedded in paraffin, and sliced into $4 \mu \mathrm{m}$ section. Pathological changes were detected by H\&E staining, hematoxylin staining for 5-10 min and eosin staining for $1 \mathrm{~min}$ at room temperature (Beijing Solarbio Science \& Technology Co., Ltd., Beijing, China). The hippocampus in brain sections was observed under a light microscope and the magnification was x200 (Olympus Corporation, Tokyo, Japan).

Immunohistochemical analysis. Sections (thickness, $4 \mu \mathrm{m}$ ) were dewaxed with various concentrations of xylene and ethanol (xylene for $10 \mathrm{~min}$, xylene for $5 \mathrm{~min}, 100 \%$ ethanol for $5 \mathrm{~min}, 95 \%$ ethanol for $2 \mathrm{~min}, 80 \%$ ethanol for $2 \mathrm{~min}$ and $70 \%$ ethanol for $2 \mathrm{~min}$ ). Sections were incubated with biotin-labeled rabbit anti-rat IgG (dilution 1:1,000; cat. no. RS030826; ImmunoWay Biotechnology Company, Plano, TX, USA) at $4^{\circ} \mathrm{C}$ overnight. Subsequent to being washed three times with PBS, sections were incubated with horseradish peroxidase (HRP)-conjugated streptomycin secondary antibody (1:200; cat. no. SE068; Beijing Solarbio Science \& Technology Co., Ltd.) for $2 \mathrm{~h}$ at room temperature. Nuclei were stained with $0.5 \%$ hematoxylin for $5 \mathrm{~min}$ at room temperature. Brown staining indicated positive cells and blue staining indicated nuclei. The brain sections were observed under a light microscope and the magnification was x200 (Olympus Corporation).

TdT-mediated dUTP nick-end labeling (TUNEL) staining. A colorimetric TUNEL apoptosis assay kit was purchased from Beyotime Institute of Biotechnology to detect apoptosis in hippocampal neurons in the brain tissues. Experiments were performed according to the manufacturer's protocol. Briefly, samples were fixed at room temperature for one day in $4 \%$ paraformaldehyde, slides were dewaxed with various concentrations of xylene and ethanol (xylene for $10 \mathrm{~min}$, xylene for $5 \mathrm{~min}, 100 \%$ ethanol for $5 \mathrm{~min}, 95 \%$ ethanol for $2 \mathrm{~min}, 80 \%$ ethanol for $2 \mathrm{~min}$ and $70 \%$ ethanol for $2 \mathrm{~min}$ at room temperature), and incubated with $20 \mu \mathrm{g} / \mathrm{ml}$ proteinase $\mathrm{K}$ (DNase free) for $30 \mathrm{~min}$ at $37^{\circ} \mathrm{C}$. Subsequent to being washed three times with $\mathrm{PBS}$, slides were incubated with $3 \% \mathrm{H}_{2} \mathrm{O}_{2}$ for $20 \mathrm{~min}$ at room temperature to inactivate the endogenous peroxidase. Following washing, slides were incubated with $50 \mu \mathrm{l}$ TUNEL reaction mixture for $60 \mathrm{~min}$ at $37^{\circ} \mathrm{C}$ in the dark, and then washed. Then, the slides were incubated with $200 \mu \mathrm{l}$ stop solution for $10 \mathrm{~min}$ at room temperature. Following this, the slides were incubated with $50 \mu \mathrm{l}$ streptavidin-HRP working solution for $30 \mathrm{~min}$ at room temperature. Subsequent to washing, the slides were 
incubated with $400 \mu 1 \mathrm{DAB}$ solution for 5-30 min at room temperature. Apoptosis-positive cells stained brown, and cell nuclei were stained with hematoxylin for $5 \mathrm{~min}$ at room temperature., which appeared blue. The degree of apoptosis was visualized via fluorescence light microscopy and the magnification was x200 (Olympus Corporation). Each slice was randomly selected over three fields.

$q P C R$. Total RNA from the brain tissues was isolated using TRIzol $^{\circledR}$ (Takara Biotechnology Co., Ltd., Dalian, China). A PrimeScript ${ }^{\mathrm{TM}}$ 1st strand cDNA synthesis kit (Takara Biotechnology Co., Ltd.) was used to synthesize cDNA. The reaction mixture included the following: $1 \mu 150 \mu \mathrm{M}$ oligo dT primers; $1 \mu \mathrm{ldNTP}$ mixture; and $1 \mu \mathrm{g}$ template RNA. Then, RNase-free $\mathrm{dH}_{2} \mathrm{O}$ was added to make up $10 \mu \mathrm{l}$ total volume, followed by incubation at $65^{\circ} \mathrm{C}$ for $5 \mathrm{~min}$, and then cooling on ice. Secondly, $10 \mu 1$ reaction mixture, $4 \mu 15 \mathrm{X}$ PrimeScript buffer, $0.5 \mu 1$ RNase inhibitor, and $1 \mu 1$ PrimeScript RTase were combined, then RNase-free $\mathrm{dH}_{2} \mathrm{O}$ was added to make up a total reaction volume of $20 \mu \mathrm{l}$, followed by incubation at $30^{\circ} \mathrm{C}$ for $5 \mathrm{~min}, 42^{\circ} \mathrm{C}$ for $30 \mathrm{~min}$, and then $95^{\circ} \mathrm{C}$ for $5 \mathrm{~min}$. qPCR was performed by using SYBR Fast qPCR Mix (Takara Biotechnology Co., Ltd.) with an ABI 7300 PCR system. The reaction protocol including the following: $10 \mu \mathrm{l}$ SYBR Fast qPCR Mix (2X); $0.8 \mu \mathrm{l}$ PCR forward primer $(10 \mu \mathrm{M}) ; 0.8 \mu \mathrm{l}$ PCR reverse primer $(10 \mu \mathrm{M}) ; 0.4 \mu 1$ ROX reference dye (50X); $1 \mu \mathrm{l} \mathrm{cDNA}$; and $\mathrm{dH}_{2} \mathrm{O}$ up to $20 \mu \mathrm{l}$. The PCR thermocycler conditions were as follows: $95^{\circ} \mathrm{C}$ for $30 \mathrm{sec}$, followed by 40 cycles: Denaturation at $95^{\circ} \mathrm{C}$ for $5 \mathrm{sec}$ and annealing at $60^{\circ} \mathrm{C}$ for $10 \mathrm{sec}$. Relative expression was calculated using the $2^{-\Delta \Delta C q}$ formula (30). Data were normalized to the $\beta$-actin gene. The following primers were used: BI-1 forward, ACGGAC TCTGGAACCATGAA; BI-1 reverse, AGCCGCCACAAA CATACAA; GPP78 forward, CCACCAGGATGCAGACAT TG; GPP78 reverse, AGGGCCTCCACTTCCATAGA; IRE1 forward, AAGTTTTGGAAGAGCCAGCA; IRE1 reverse, TGTTCTTGCCTCCAAGTGTG; JNK forward, CGGAAC ACCTTGTCCTGAA; JNK reverse, TCGCCTGACTGG CTTTAAGT; ASK forward, ATCCCAGAGTCCATGTCT GC; ASK reverse, GCAACCACATACCCGAGAGT; CHOP forward, AGCAGAGGTCACAAGCACCT; CHOP reverse, CTGCTCCTTCTCCTTCAGC.

Western blot analysis. Proteins from the brain tissues were extracted via lysis buffer (Beyotime Institute of Biotechnology). The total protein concentrations were determined using a BCA protein assay kit (Beyotime Institute of Biotechnology). Proteins (30 $\mu \mathrm{g})$ were separated by $10 \%$ SDS-PAGE gels and transferred to polyvinylidene fluoride membranes. Membranes were blocked with $10 \%$ skimmed milk in TBST (TBS containing $0.1 \%$ Tween-20) at room temperature for $1.5 \mathrm{~h}$. Following blocking, membranes were incubated with primary antibodies, followed by HRP Goat Anti-Rabbit IgG (H+L) secondary antibodies (dilution 1:2,000; cat. no. AS014; ABclonal Biotech Co., Ltd., Wuhan, China) or HRP Goat Anti-Mouse IgG $(\mathrm{H}+\mathrm{L})$ secondary antibodies (dilution 1:2,000; cat. no. AS003; ABclonal Biotech Co., Ltd.). The following primary antibodies were used: BI-1 antibody (dilution 1:1,000; cat. no. sc-73483; Santa Cruz Biotechnology, Inc., Dallas, TX, USA), CHOP antibody (dilution 1:1,000; cat. no. A11346, ABclonal, Biotech), GPR78 antibody (dilution 1:1,000; cat. no. A12364; ABclonal Biotech), IRE1 $\alpha$ antibody (dilution 1:1,000; cat. no. 37073; Abcam, Cambridge, MA, USA), JNK antibody (dilution 1:1,000; cat. no. A2462; ABclonal Biotech), ASK1 antibody (dilution 1:1,000; cat. no. A6274; ABclonal Biotech), caspase 3 (dilution 1:1,000; cat. no. A11319; ABclonal Biotech), caspase 9 (dilution 1:1,000; cat. no. A7523; ABclonal Biotech) and albumin (dilution 1:500; cat. no. A0353; ABclonal Biotech). Subsequently, the bands were visualized by enhanced chemiluminescence (Advansta, Inc. Menlo Park, CA, USA). The densities of the bands were detected using Image $J$ 2x software (National Institutes of Health, Bethesda, MD, USA), and normalized to $\beta$-actin.

Statistical analysis. Data are expressed as the mean \pm standard deviation. The GraphPad Prism software version 5.0a (GraphPad Software, Inc., La Jolla, CA, USA) was used for statistical analysis. One-way analysis of variance, followed by Tukey's Multiple Comparison post hoc test, was used to analyze the differences among the groups. $\mathrm{P}<0.05$ was considered to indicate a statistically significant difference.

\section{Results}

Neurological scoring and brain water content. As indicated in Fig. 1A, the SAH model groups demonstrated markedly decreased neurological scores compared with the control and sham groups, and the SAH $24 \mathrm{~h}$ group exhibited lower neurological scores compared with all the other groups. In Fig. 1B, it was indicated that the brain water indexes in the SAH model groups were increased compared with those of the control and sham groups. In addition, the SAH $24 \mathrm{~h}$ group exhibited the highest brain water index compared with the SAH $48 \mathrm{~h}$ and $72 \mathrm{~h}$ groups. Therefore, it was concluded that the SAH $24 \mathrm{~h}$ model was the most effective.

Pathological analysis of hippocampal neurons. In the control and sham groups, the hippocampal neurons were aligned in a well-ordered manner, with normal morphology and without heteromorphic neurons (Fig. 2). Compared with the sham group, the SAH 24, 48 or $72 \mathrm{~h}$ groups exhibited an increased number of heteromorphic neurons in the hippocampus (Fig. 2). Additionally, the SAH $24 \mathrm{~h}$ group had the highest number of heteromorphic neurons compared with the other groups (Fig. 2). This result indicated that SAH may induce brain injury. According to the aforementioned results, the optimum SAH time $(24 \mathrm{~h})$ was selected for subsequent SAH model experiments.

Expression levels of BI-1 in brain tissues following SAH. To investigate the expression of BI-1 in brain tissues following $\mathrm{SAH}, \mathrm{qPCR}$ and western blot analysis were used to detect the changes in BI-1 in all groups. It was identified that the levels of BI-1 in the brain tissues were significantly suppressed following SAH compared with those of the sham group, and the level of BI-1 was the lowest at $24 \mathrm{~h}$ after SAH (Fig. 3). These results indicated that BI-1 expression was associated with early brain injury following SAH, and this expression may have an important role in brain injury repair. 

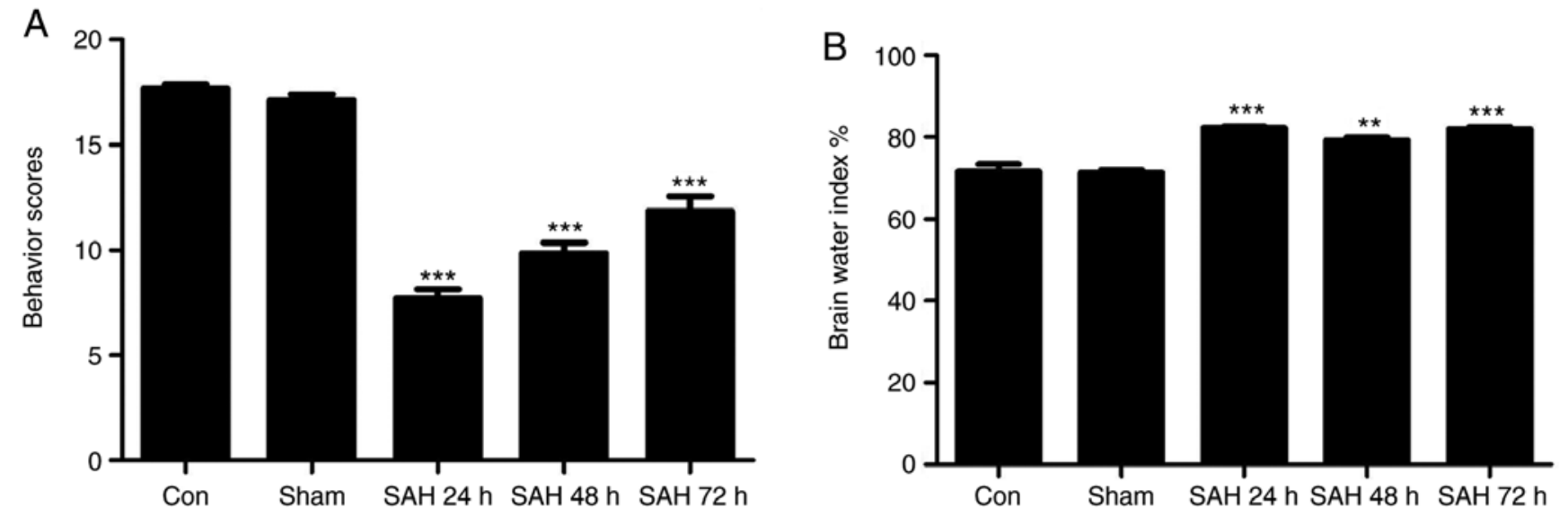

Figure 1. Neurological score and brain edema assessments in rats at different time points during early brain injury following SAH. (A) Neurological scores were analyzed at 24, 48 and $72 \mathrm{~h}$. (B) Brain water indexes were analyzed by measuring the brain water content. All experiments were repeated at least three times. All data are presented as the mean \pm standard deviation. ${ }^{* *} \mathrm{P}<0.01$ and ${ }^{* * * *} \mathrm{P}<0.001$ vs. control group. $\mathrm{SAH}$, subarachnoid hemorrhage.
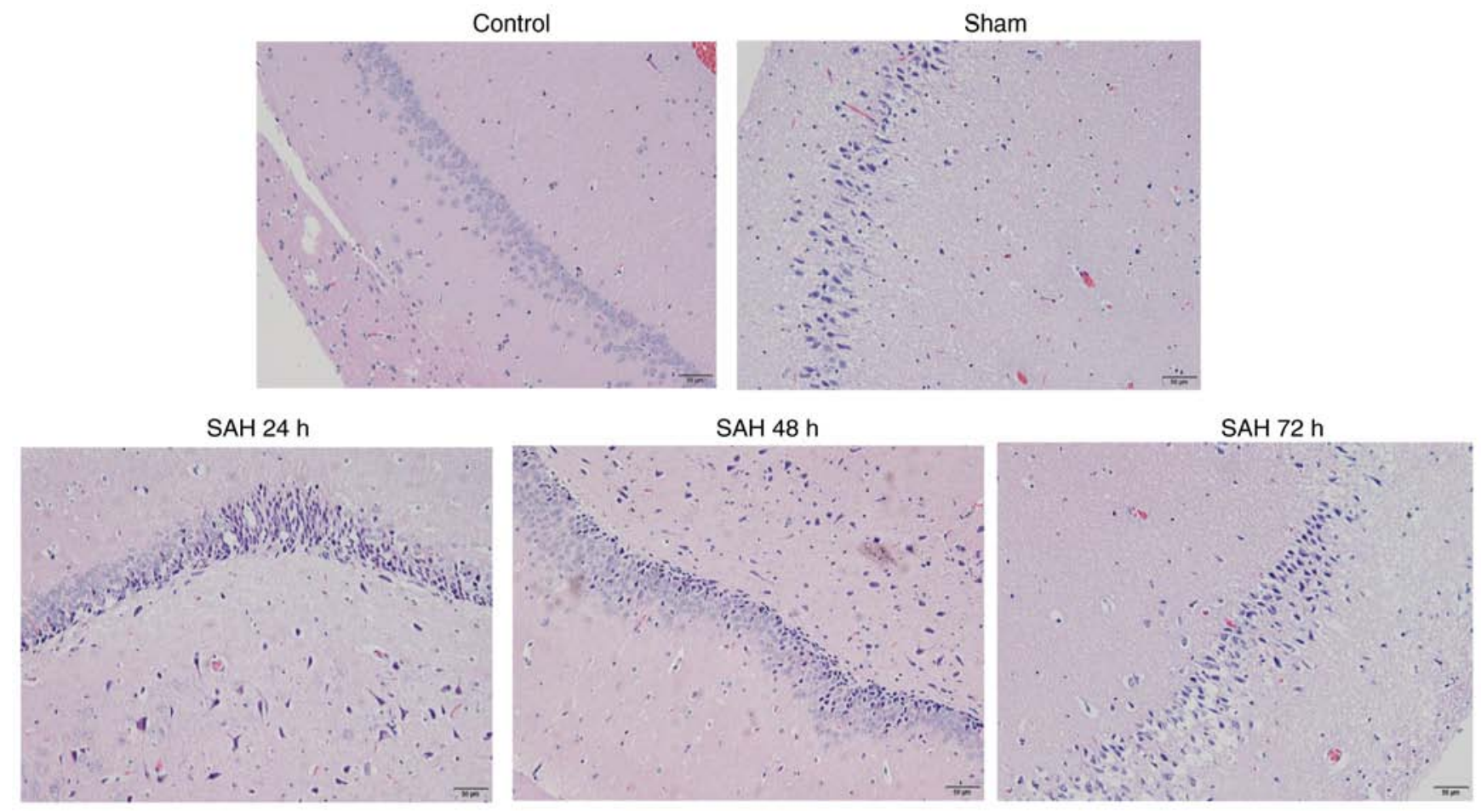

Figure 2. H\&E staining of rats at different time points during early brain injury following SAH. Normal and heteromorphic neurons in the hippocampus of the brains were detected by H\&E staining (magnification, $\mathrm{x} 200$ ) in the control, sham, and 24, 48 and $72 \mathrm{~h}$ SAH groups. Scale bar=50 $\mu \mathrm{m}$. H\&E, hematoxylin and eosin; SAH, subarachnoid hemorrhage.

Effects of BI-1 shRNA and BI-1 overexpression on neurological scores, brain water index, $H \& E$ staining and $B B B$ permeability. The BI-1 levels in negative control (NC), pCDH, BI-1/pCDH, BI-1/pLKO.1 shRNA and scrambled shRNA/pLKO.1 cells were examined prior to use in the animal model. As demonstrated in Fig. 4A-C, the mRNA and protein levels of BI-1 were markedly increased in the $\mathrm{BI}-1 / \mathrm{pCDH}$ group compared with that in other groups, and decreased in BI-1/pLKO.1 shRNA group compared with that in other groups. Furthermore, there were no differences detected among the NC, pCDH and scramble shRNA/pLKO.1 groups (Fig. 4A-C). As no differences were detected among the NC, pCDH and scrambled shRNA/pLKO.1 groups, only a single control group (the NC group) was used in the subsequent animal experiments.

The neurological scores were significantly decreased in the SAH+BI-1 shRNA group and increased in the SAH+BI-1 over group compared with those in the SAH group (Fig. 4D). The brain water indexes were significantly increased in the SAH+BI-1 shRNA group and decreased in the SAH+BI-1 over group compared with those in the SAH group (Fig. 4E).

Similarly, the expression levels of albumin in the SAH group and the SAH+BI-1 shRNA group were increased compared with that in the sham group and were highest in the SAH+BI-1 shRNA group. In addition, the levels of albumin in the SAH+BI-1 over group were decreased compared with those 

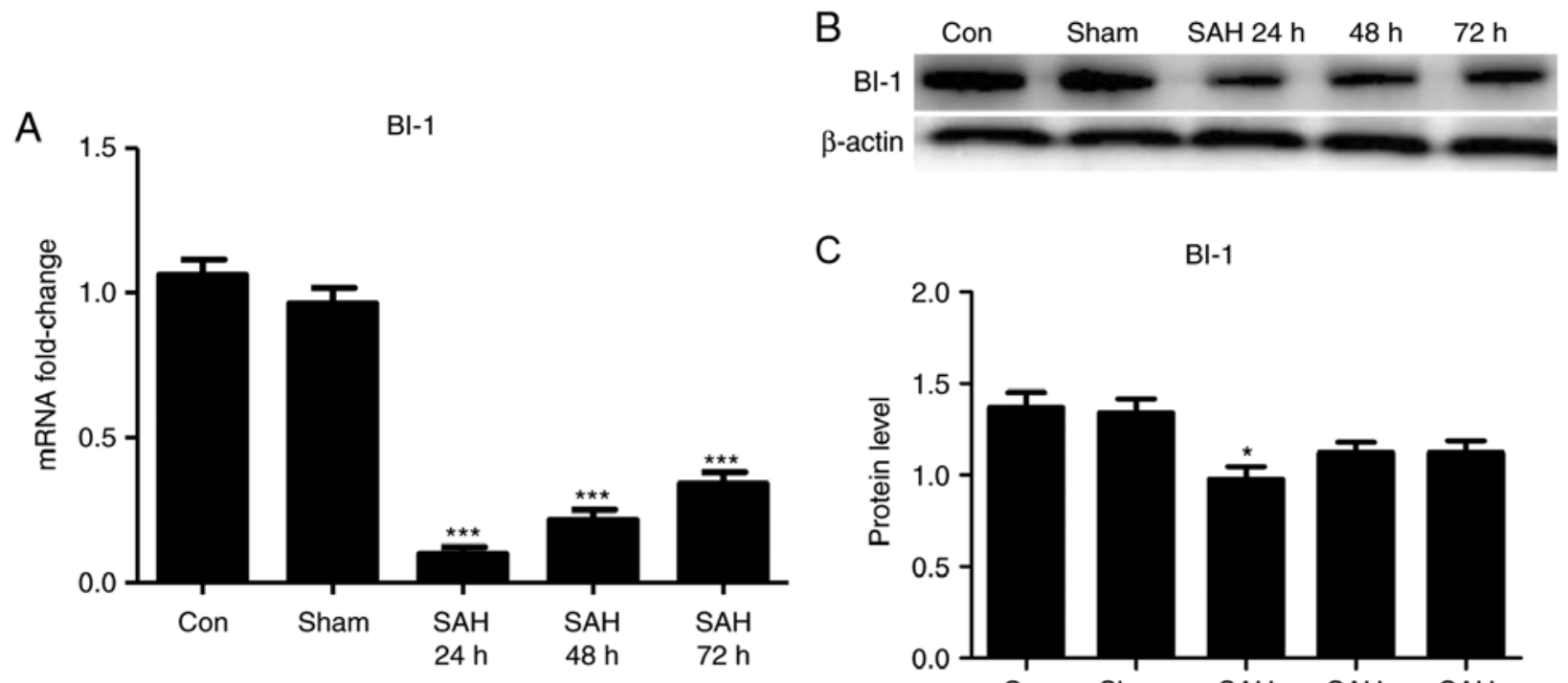

C

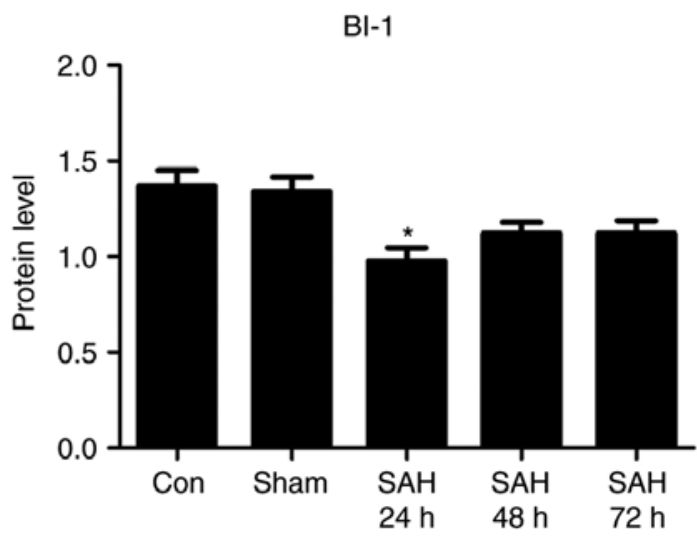

Figure 3. Expression levels of BI-1 at different time points during early brain injury following SAH. (A) The mRNA levels of BI-1 at 24,48 and $72 \mathrm{~h}$ after SAH were detected by quantitative polymerase chain reaction assay. (B) The protein levels of BI-1 at 24, 48 and $72 \mathrm{~h}$ after SAH were detected by western blot analysis. (C) Protein levels were normalized to that of $\beta$-actin. All experiments were repeated at least three times. All data are presented as the mean \pm standard deviation. ${ }^{*} \mathrm{P}<0.05$ and ${ }^{* * *} \mathrm{P}<0.001$ vs. con group. BI-1, B-cell lymphoma 2-associated X protein-inhibitor-1; con, control; SAH, subarachnoid hemorrhage.

in the SAH group but were increased compared with those in the sham group (Fig. 5A). To additionally detect BBB permeability, the levels of $\operatorname{IgG}$ in the brain tissues were also assessed by IHC assays. In Fig. 5B, it was identified that the IgG levels in the brains were increased following SAH compared with those in the sham group and highest in the SAH+BI-1 shRNA group. BI-1 overexpression significantly suppressed the IgG induced by SAH in the SAH+BI-1 over group compared with the SAH group (Fig. 5B). The quantification of IgG-positive cells was also analyzed (Fig. 5C). The results suggested that BI-1 inhibited the BBB permeability induced by brain injury following SAH.

As indicated in Fig. 6, the SAH group and the $\mathrm{SAH}+\mathrm{NC}$ group contained increased numbers of heteromorphic neurons compared with the sham group, and the number of heteromorphic neurons in the SAH+BI-1 shRNA group was increased compared with that in the SAH and SAN+NC groups. However, the SAH+BI-1 over group exhibited a decreased number of heteromorphic neurons compared with the SAH+BI-1 shRNA group, but this number was increased compared with that in the sham group. These results implied that BI-1 repaired and rescued brain injury following SAH.

Effects of BI-1 shRNA and BI-1 overexpression on ER stress-associated apoptosis. To demonstrate the effects of BI-1 on apoptosis, TUNEL assays of brain tissues were performed. The number of apoptosis-positive cells was markedly increased in the SAH group and the $\mathrm{SAH}+\mathrm{NC}$ group compared with the sham group, and BI-1 shRNA significantly attenuated apoptosis in the SAH+ BI-1 shRNA group compared with the SAH group (Fig. 7A). However, BI-1 overexpression significantly rescued the high levels of apoptosis in the SAH+ BI-1 over group compared with the SAH group (Fig. 7A). This result suggested that BI-1 may inhibit the apoptosis induced by SAH. The percentage of TUNEL-positive cells was also analyzed
(Fig. 7B). The expression levels of apoptosis-associated proteins caspase 3 and caspase 9 in these groups via western blot analysis. These results were consistent with TUNEL assays (Fig. 7C and D).

To additionally investigate the mechanism of apoptosis, the expression levels of ER stress-associated genes (GPR78, CHOP, IRE1, JNK and ASK1) were analyzed using qPCR and western blot analysis. As indicated in Fig. 8, the levels of GPR78, CHOP, IRE1, JNK and ASK1 were increased in the SAH group compared with those in the sham group, and were also increased in the SAH+BI-1 shRNA group compared with those in the SAH group. The expression levels of all genes were decreased in SAH+BI-1 over group compared with those in the SAH group; however, these levels were increased compared with those in the sham group. No difference between the SAH and $\mathrm{SAH}+\mathrm{NC}$ groups was observed. These results indicated that BI-1 may inhibit ER stress-associated apoptosis induced by SAH.

\section{Discussion}

The present study examined the neuroprotective and anti-apoptotic effects of BI-1 on EBI following SAH in a rat model. It was identified that BI-1 overexpression markedly increased neurological scores, and decreased the brain water index and the number of heteromorphic neurons in the hippocampal area. Furthermore, BI-1 overexpression also restored BBB function and suppressed the ER stress-mediated apoptosis induced by EBI following SAH in the hippocampal area. By contrast, BI-1 shRNA demonstrated the opposite results.

EBI is regarded as an important and potential implementation target of treatment for SAH due to pathophysiological variables occurring during the EBI period, defined as the first $72 \mathrm{~h}$ after SAH $(2,6)$. During the EBI period, a number of physiological disruptions occur, including increased ICP, 

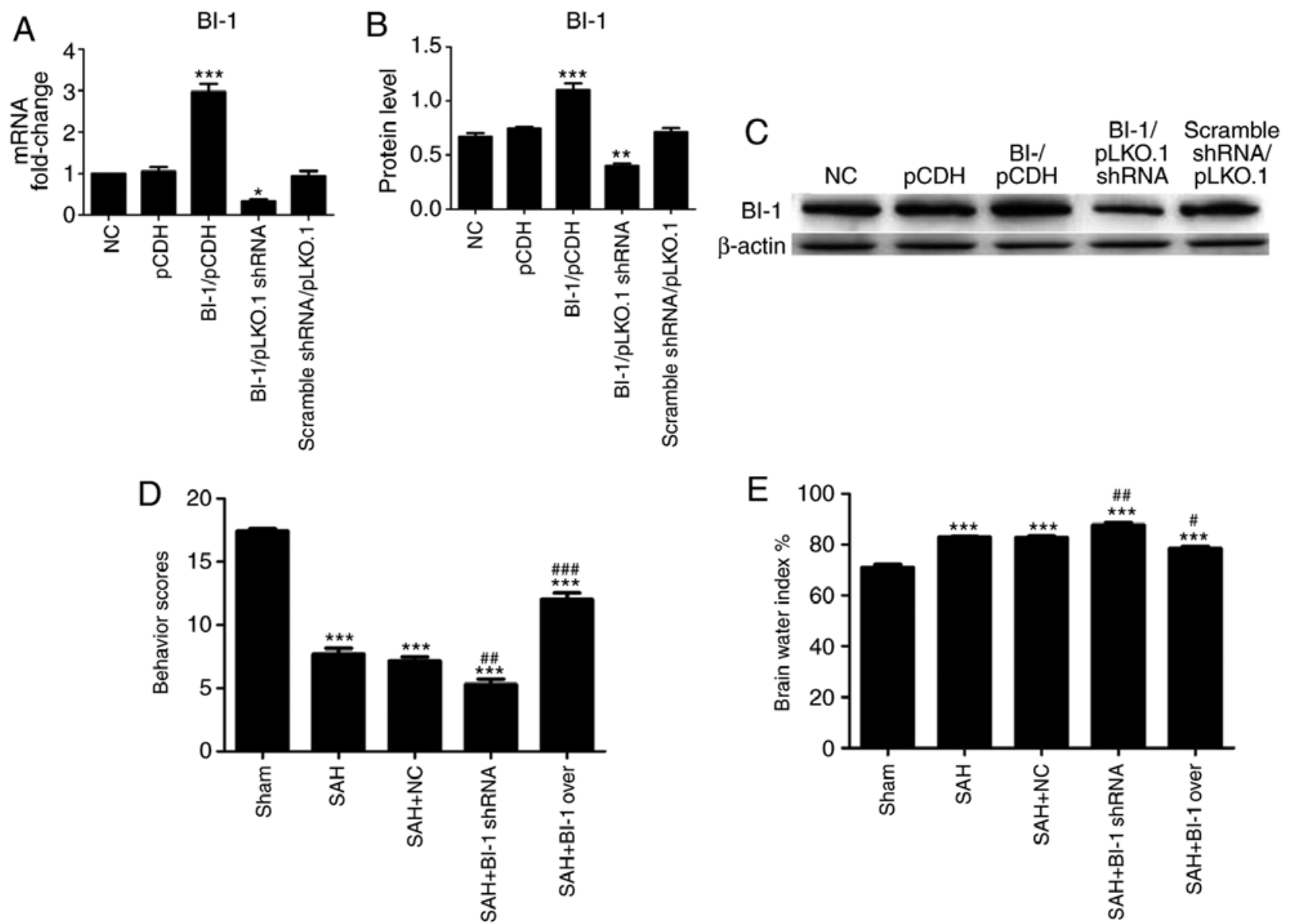

Figure 4. Effects of BI-1 on neurological scores and brain edema in EBI following SAH. The mRNA and protein levels of BI-1 in NC, pCDH, BI-1/pCDH, BI-1/pLKO.1 shRNA and scrambled shRNA/pLKO.1 cells were detected by (A) quantitative polymerase chain reaction and (B) western blot analysis. (C) Protein levels were normalized to that of $\beta$-actin. (D) Neurological scores were analyzed at 24,48 and $72 \mathrm{~h}$. (E) Brain water indexes were analyzed by measuring the brain water content. All experiments were repeated at least three times. All data are presented as the mean \pm standard deviation. ${ }^{*} \mathrm{P}<0.05,{ }^{* *} \mathrm{P}<0.01$ and ${ }^{* * *} \mathrm{P}<0.001$ vs. the $\mathrm{NC} /$ sham groups. ${ }^{\#} \mathrm{P}<0.05,{ }^{\# \#} \mathrm{P}<0.01$ and ${ }^{\# \# \#} \mathrm{P}<0.001$ vs. the SAH group. NC, negative control; BI-1, B-cell lymphoma 2 -associated $\mathrm{X}$ protein-inhibitor-1; shRNA, short hairpin RNA; SAH, subarachnoid hemorrhage; SAH+BI-1 over, SAH + BI-1 overexpression.

decreased CBF, brain edema, BBB disruption, inflammation and oxidative cascades that all ultimately lead to cell death (4). Neurological scores are associated with the pathophysiological aspects of SAH. The present study first evaluated the neurological scores of rats following $\mathrm{SAH}$, and the lowest scores were observed at $24 \mathrm{~h}$ after SAH compared with those at 48 and $72 \mathrm{~h}$. Brain edema was assessed by brain water content. The highest brain water index was measured at $24 \mathrm{~h}$ after $\mathrm{SAH}$ compared with those of the other groups. The H\&E staining results were also consistent with these data. The levels of BI-1 in the brain tissues at 24, 48 and $72 \mathrm{~h}$ after SAH were also determined. The levels of BI-1 at $24 \mathrm{~h}$ were decreased compared with those of the other groups. This result indicated that BI-1 exhibited a positive effect on brain tissues following $\mathrm{SAH}$ and alleviated EBI. Therefore, $24 \mathrm{~h}$ after SAH was selected the optimal time period for subsequent experiments in the present study.

BI-1 is an evolutionarily conserved cytoprotective protein. To additionally investigate the effect of BI-1 on EBI following SAH, SAH models were treated with BI-1 overexpression and shRNA plasmids. Neurological scores were significantly increased and the brain water index was decreased in the $\mathrm{SAH}+\mathrm{BI}-1$ over group compared with those in the SAH group.
However, BI-1 shRNA significantly decreased the neurological scores and increased the brain water index compared with those in the SAH group. Brain edema has been considered to have a direct effect on BBB disruption (2). The aforementioned results suggested that BI-1 has an important function in limiting EBI following SAH.

In addition to brain water content, the levels of albumin and IgG in brain tissues are also hallmarks of BBB integrity $(31,32)$. Under normal circumstances, the albumin serum protein $\mathrm{IgG}$ cannot completely permeate the BBB. However, following cerebral injury, albumin and IgG may permeate the brain tissue, indicating that the BBB integrity has been damaged and permeability is increased $(33,34)$. Therefore, the expression of albumin and $\mathrm{IgG}$ extravasation in brain tissue may be detected to reflect the injury and permeability of the BBB. The present study detected albumin levels using western blot analysis, and detected IgG levels using immunohistochemical assays. The levels of albumin were markedly increased in the SAH group compared with those in the sham group. In addition, the levels of albumin decreased in the SAH+BI-1 over group and increased in the SAH+BI-1 shRNA group compared with those in the SAH group. Using IgG immunohistochemistry, positively-stained neuronal cells in the hippocampal area were 

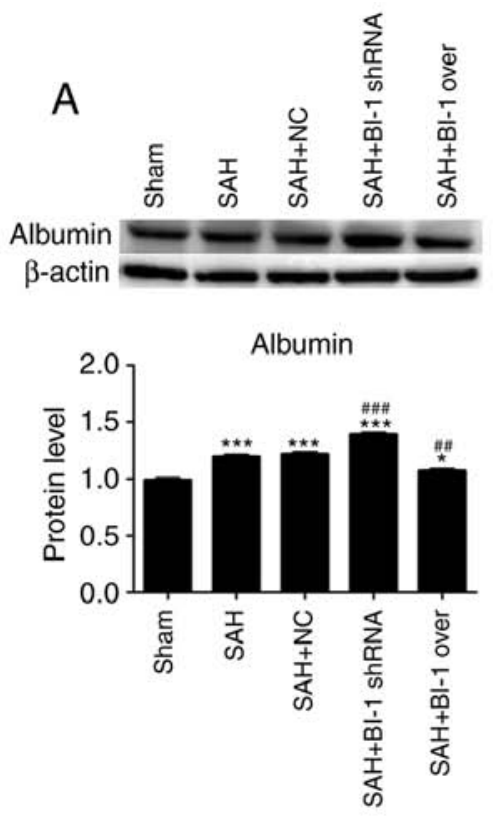

B
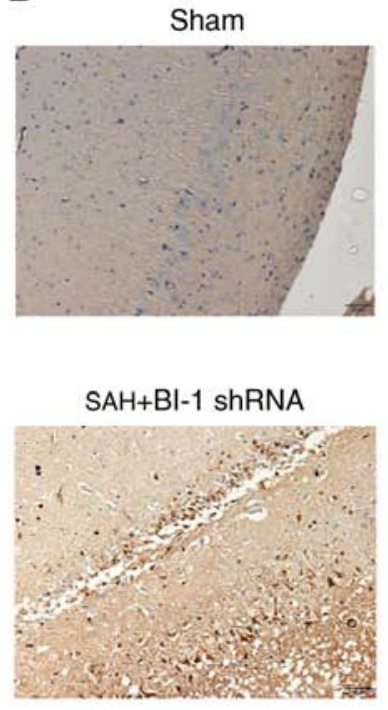

$\mathrm{SAH}$

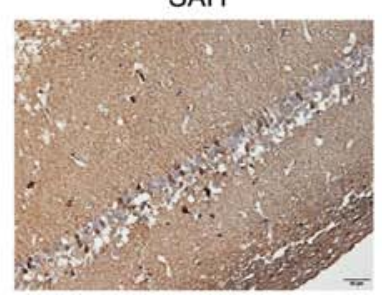

$\mathrm{SAH}+\mathrm{BI}-1$ over

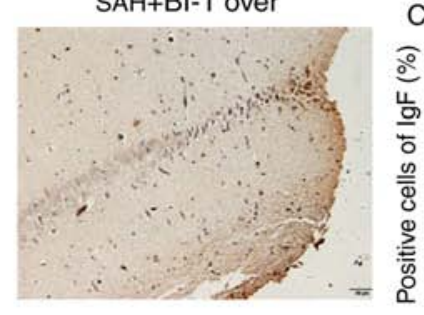

C
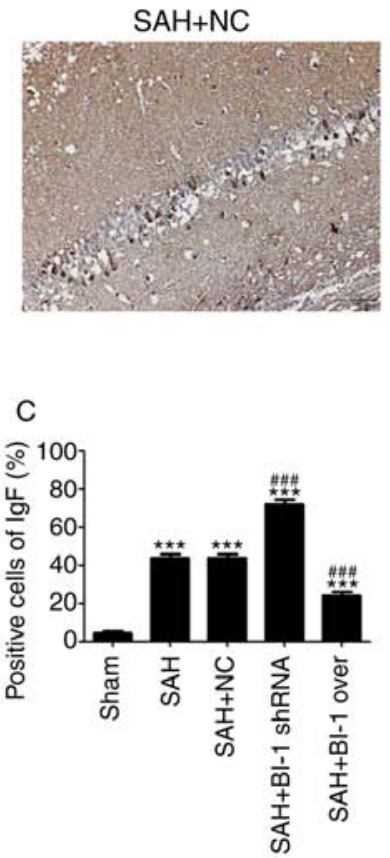

Figure 5. Effects of BI-1 on blood-brain barrier injury during EBI following SAH. (A) The expression levels of albumin following BI-1 overexpression and shRNA silencing were detected by western blot analysis. (B) Immunohistochemistry of the hippocampus in the sham, SAH, SAH+NC, SAH+BI-1 shRNA and SAH+BI-1 over groups. Scale bar=50 $\mu \mathrm{m}$ (magnification, $\mathrm{x} 200$ ). (C) Quantification of immunohistochemical positive cells, expressed as the total cell percentage. All data are presented as the mean \pm standard deviation. ${ }^{*} \mathrm{P}<0.05$ and ${ }^{* * *} \mathrm{P}<0.001$ vs. the sham group, ${ }^{\# \#} \mathrm{P}<0.01$ and ${ }^{\# \# \#} \mathrm{P}<0.001$ vs. the $\mathrm{SAH}$ group. BI-1, B-cell lymphoma 2-associated X protein-inhibitor-1; shRNA, short hairpin RNA; SAH, subarachnoid hemorrhage; SAH+BI-1 over, SAH + BI-1 overexpression; NC, negative control.

Sham

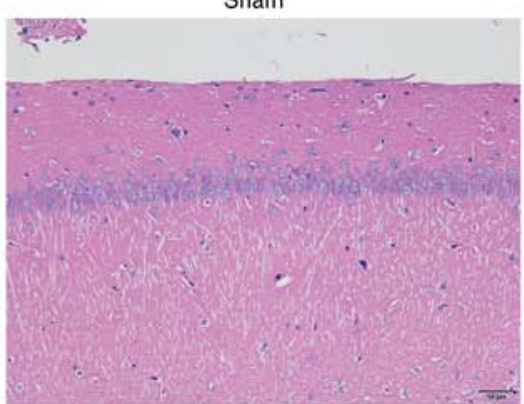

SAH

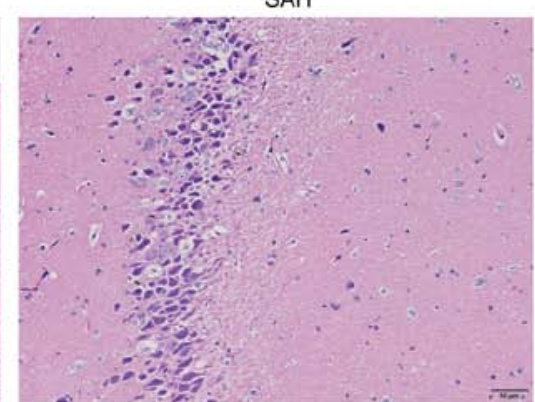

$\mathrm{SAH}+\mathrm{NC}$

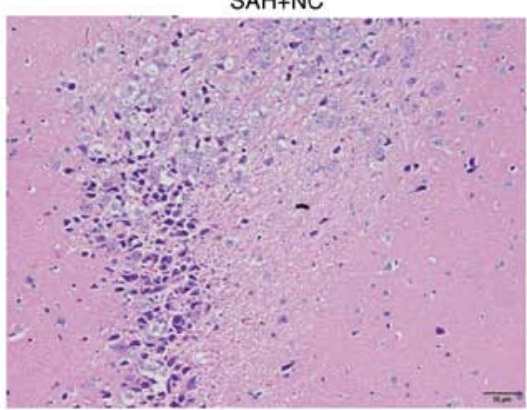

$\mathrm{SAH}+\mathrm{BI}-1$ ShRNA

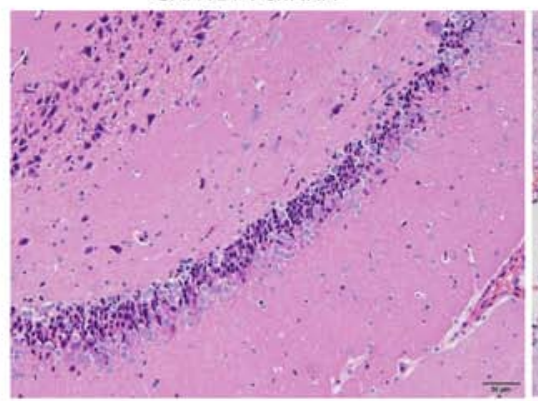

$\mathrm{SAH}+\mathrm{BI}-1$ over

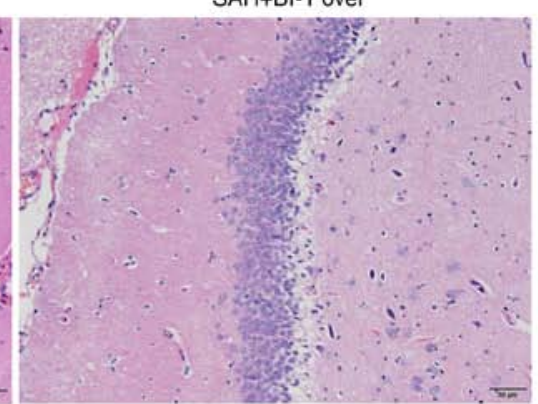

Figure 6. H\&E staining of rats following BI-1 overexpression and shRNA silencing. Normal and heteromorphic neurons in the hippocampus of the brains were detected by H\&E staining in the sham, SAH, SAH+NC, SAH+BI-1 shRNA and SAH+BI-1 over groups. Scale bar=50 $\mu$ m (magnification, x200). H\&E, hematoxylin and eosin; BI-1, B-cell lymphoma 2-associated X protein-inhibitor-1; shRNA, short hairpin RNA; SAH, subarachnoid hemorrhage; SAH+BI-1 over, SAH + BI-1 overexpression; NC, negative control.

detected in the SAH group, revealing increased permeability of the BBB. The SAH+BI-1 over group exhibited markedly less positive neuronal cells compared with the SAH group, and the SAH+BI-1 shRNA group exhibited more positive neurons compared with the SAH group. This result suggested that BI-1 may repair and alleviate BBB damage induced by 
A

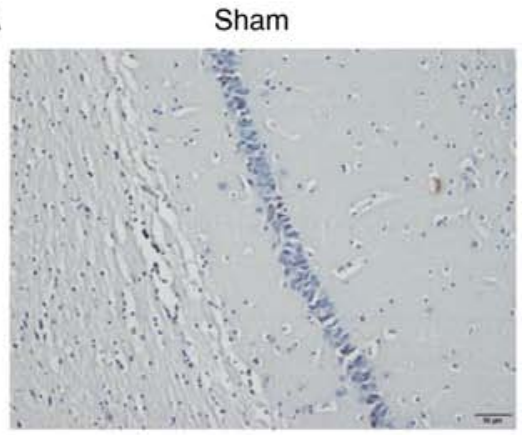

\section{SAH+BI-1 ShRNA}

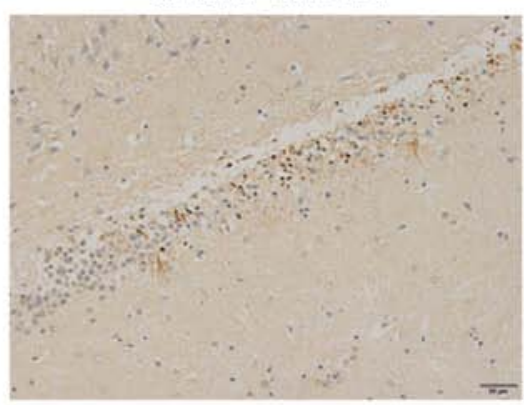

$\mathrm{SAH}$

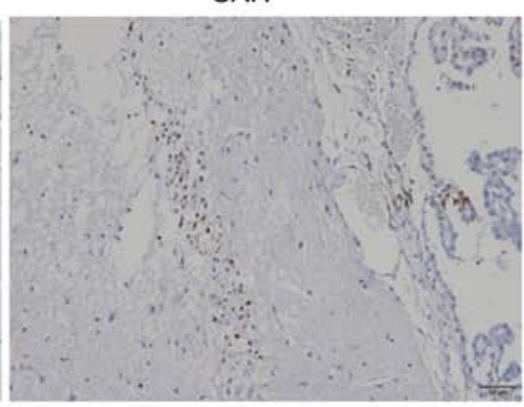

$\mathrm{SAH}+\mathrm{NC}$

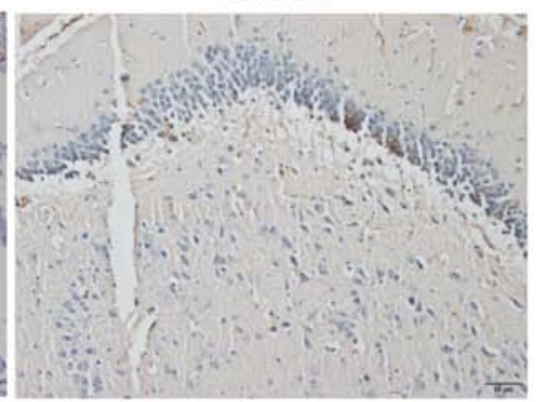

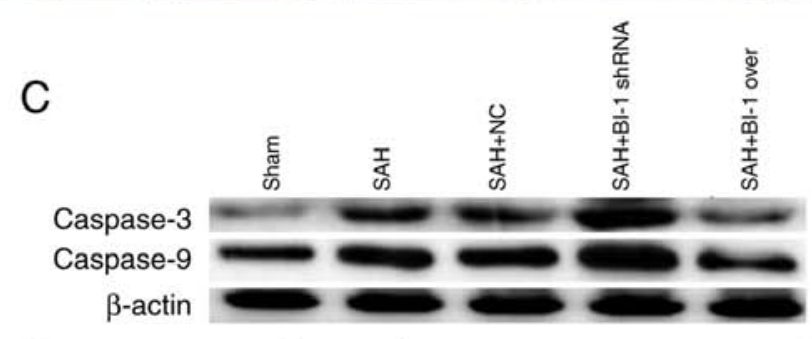

B

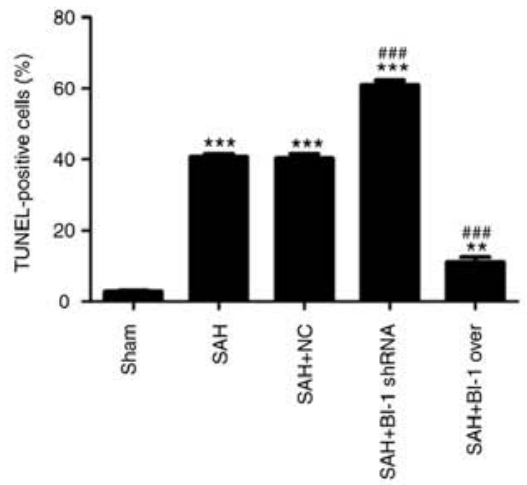

$\mathrm{D}$

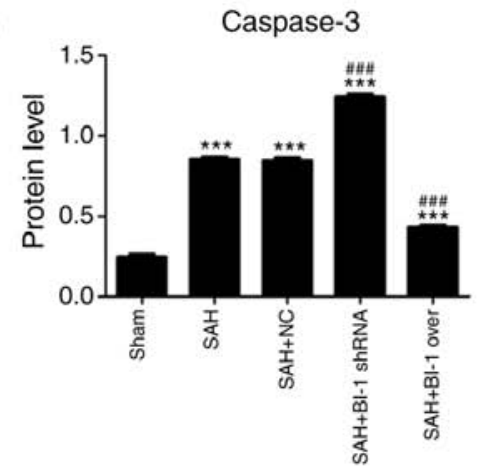

$\mathrm{SAH}+\mathrm{BI}-1$ over

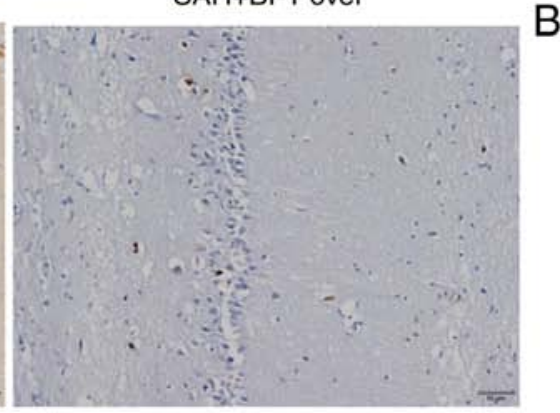

$=$
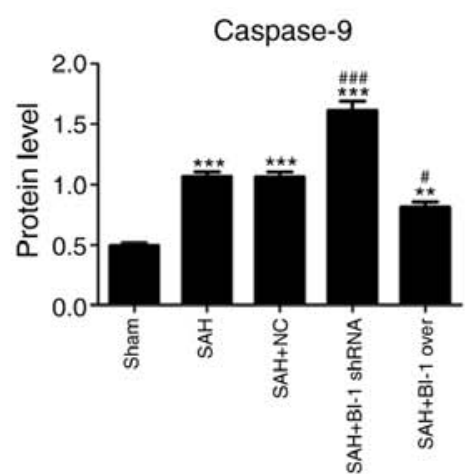

Figure 7. Effects of BI-1 on apoptosis in the hippocampus following BI-1 overexpression and shRNA silencing. (A) Representative TUNEL photomicrographs of the hippocampus in the sham, SAH, SAH+NC, SAH+BI-1 shRNA and SAH+BI-1 over groups. Scale bar=50 $\mu$ m. (B) Quantification of TUNEL-positive cells in these groups, expressed as the total cell percentage. (C) The protein levels of caspase 3 and caspase 9 were detected by western blot analysis. (D) Protein levels were normalized to that of $\beta$-actin. All data are presented as the mean \pm standard deviation. ${ }^{* *} \mathrm{P}<0.01$ and ${ }^{* * * *} \mathrm{P}<0.001$ vs. the sham group. ${ }^{*} \mathrm{P}<0.05$ and

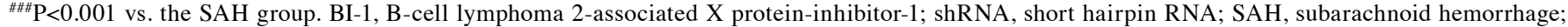
SAH+BI-1 over, SAH + BI-1 overexpression; NC, negative control; TUNEL, terminal deoxynucleotidyl transferase-mediated dUTP nick-end labeling.

EBI following SAH. As indicated in the results of the H\&E staining, these data were consistent with the aforementioned results.

Previous studies suggested that EBI is one of the important factors affecting poor prognosis following SAH $(35,36)$, and EBI is involved in a number of processes, including apoptosis, oxidative stress and neuroinflammation $(7,37,38)$. It has also been suggested that the apoptosis of neuronal cells is an important factor in EBI following $\mathrm{SAH}$, which may explain the serious outcomes of SAH $(39,40)$. In the present study, the effect of BI-1 on apoptosis in EBI following SAH was examined via TUNEL assays. It was identified that the SAH group exhibited more TUNEL-positive neuronal cells in the hippocampal area compared with the sham group. BI-1 significantly inhibited the number of TUNEL-positive neuronal cells in the $\mathrm{SAH}+\mathrm{BI}-1$ over group compared with the SAH group, and the opposite results were observed in the SAH+BI-shRNA group.

ER stress is associated with various human neurodegenerative diseases (41). Downstream factors of ER stress may induce neuronal apoptosis following SAH (42). However, certain 

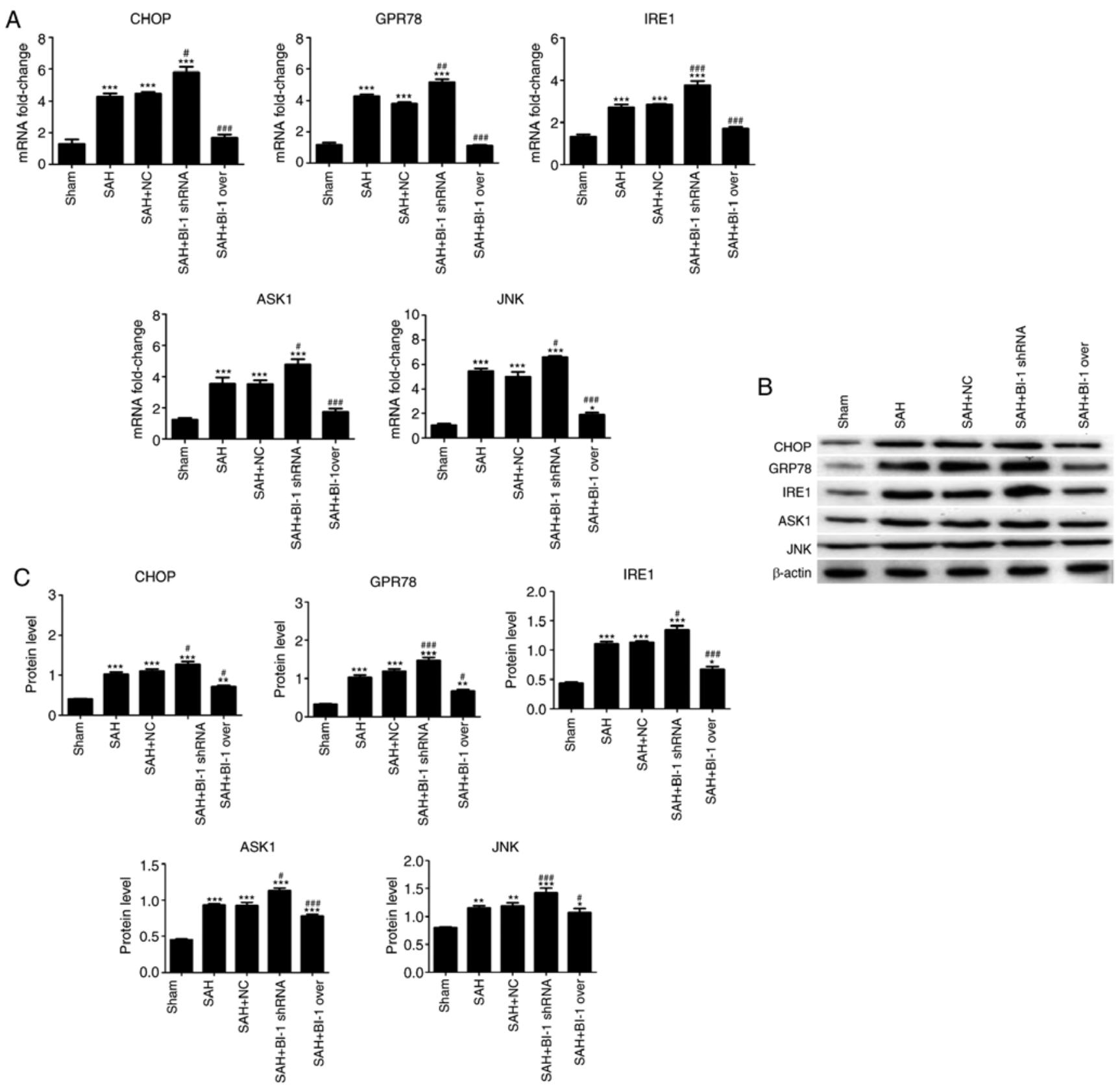

Figure 8. Potential mechanism of the effects of BI-1 on apoptosis induced by early brain injury following SAH. (A) The mRNA levels of GPR78, CHOP, IRE-1, JNK and ASK1 were detected by quantitative polymerase chain reaction assays. (B) The protein levels of GPR78, CHOP, IRE-1, JNK and ASK1 were detected by western blot analysis. (C) Protein levels were normalized to that of $\beta$-actin. All experiments were repeated at least three times. All data are presented as the mean \pm standard deviation. ${ }^{*} \mathrm{P}<0.05,{ }^{* *} \mathrm{P}<0.01$ and ${ }^{* * *} \mathrm{P}<0.001$ vs. the control group. ${ }^{\#} \mathrm{P}<0.05,{ }^{* \#} \mathrm{P}<0.01$ and ${ }^{\# \# \# "} \mathrm{P}<0.001$ vs. the SAH group. BI-1, B-cell lymphoma 2-associated X protein-inhibitor-1; shRNA, short hairpin RNA; SAH, subarachnoid hemorrhage; SAH+BI-1 over, SAH + BI-1 overexpression; NC, negative control; CHOP, C/EBP homologous protein; GRP78, Glucose regulated protein, 78 kDa; IRE1, Serine/threonine-protein kinase/endoribonuclease IRE1; ASK1, apoptotic signaling kinase-1; JNK, c-Jun N terminal kinases.

previous studies have suggested that ER stress is induced in cerebral ischemia and that ER stress-mediated reactions may inhibit neuronal apoptosis (43). ER stress appears to serve dual roles in neuronal apoptosis $(44,45)$. Therefore, the present study aimed to investigate the association between ER stress and apoptosis in EBI following SAH. The levels of ER stress signaling genes, namely GPR78, CHOP, IRE-1, JNK and ASK1, which are associated with ER stress, were examined via $\mathrm{QPCR}$ and western blot analysis. The results suggested that ER stress-mediated apoptosis was markedly induced in the SAH group compared with the sham groups. In addition,
BI-1 inhibited the ER stress-mediated apoptosis induced by EBI following SAH.

In conclusion, the results from the present study demonstrate that BI-1 exerts a neuroprotective effect on EBI following SAH by suppressing apoptosis. The overexpression of BI-1 alleviated EBI following SAH and apoptosis, suggesting that BI-1 may represent a potential therapeutic strategy for EBI following SAH. It was also demonstrated that ER stress mediated-apoptosis served an important role in SAH treatment, and BI-1 may inhibit EBI following SAH by suppressing an apoptotic pathway associated with ER stress. Mitochondria-derived 
stresses are also associated with neuropathological and neurodegenerative diseases (46). Mitochondria are central organelles in neuronal physiology integrating several crucial functions, including energy metabolism, cell respiration and $\mathrm{Ca}^{2+}$ homeostasis, all of which have been revealed to be dysregulated in Alzheimer's disease and other neurodegenerative disorders, such as Parkinson's disease $(47,48)$. Several studies have reported that the mitochondrial pathway is closely associated with EBI following SAH $(49,50)$. Therefore, the association among BI-1, SAH and mitochondria-derived stresses will be addressed in future studies.

\section{Acknowledgements}

Not applicable.

\section{Funding}

The present study was supported by the Natural Science Foundation of China (grant no. 81560227), the Scientific Research Found Project in Yunnan Province Department of Education (grant no. 2016ZZX046), the Joint Special Project for Applied Basic Research of Yunnan Provincial Science and Technology Department-Kunming Medical University [grant no. 2017FE467(-208)], and the 'Kunhua. Aoxin' Science and Technology Project of the First People's Hospital of Yunnan Province (grant no. 2014BS009).

\section{Availability of data and materials}

The datasets used and/or analyzed during the current study are available from the corresponding author on reasonable request.

\section{Authors' contributions}

JZ and JL conceived and designed the study. JL, SZ and YZ performed the experiments. XL, WT and LJ processed data. JL and XQ wrote the manuscript. JZ, JL, SZ, YZ and XQ reviewed and edited the manuscript. All authors read and approved the manuscript.

\section{Ethics approval and consent to participate}

The animal experiments were approved by the Animals Ethics Committee of Kunming Medical University and the Guide for the Care and Use of Laboratory Animals.

\section{Patient consent for publication}

Not applicable.

\section{Competing interests}

The authors declare that they have no competing interests.

\section{References}

1. Al-Khindi T, Macdonald RL and Schweizer TA: Cognitive and functional outcome after aneurysmal subarachnoid hemorrhage. Stroke 41: e519-e536, 2010.
2. Cahill J, Calvert JW and Zhang JH: Mechanisms of early brain injury after subarachnoid hemorrhage. J Cereb Blood Flow Metab 26: 1341-1353, 2006.

3. Ayer R, Chen W, Sugawara T, Suzuki H and Zhang JH: Role of gap junctions in early brain injury following subarachnoid hemorrhage. Brain Res 1315: 150-158, 2010.

4. Fujii M, Yan J, Rolland WB, Soejima Y, Caner B and Zhang JH: Early brain injury, an evolving frontier in subarachnoid hemorrhage research. Transl Stroke Res 4: 432-446, 2013.

5. Ayer R and Zhang J: Connecting the early brain injury of aneurysmal subarachnoid hemorrhage to clinical practice. Turk Neurosurg 20: 159-166, 2010.

6. Yuksel S, Tosun YB, Cahill J and Solaroglu I: Early brain injury following aneurysmal subarachnoid hemorrhage: Emphasis on cellular apoptosis. Turk Neurosurg 22: 529-533, 2012.

7. Hasegawa Y, Suzuki H, Sozen T, Altay O and Zhang JH: Apoptotic mechanisms for neuronal cells in early brain injury after subarachnoid hemorrhage. Acta Neurochir Suppl 110: 43-48, 2011.

8. Cheng G, Chunlei W, Pei W, Zhen L and Xiangzhen L: Simvastatin activates Akt/glycogen synthase kinase-3beta signal and inhibits caspase-3 activation after experimental subarachnoid hemorrhage. Vascul Pharmacol 52: 77-83, 2010.

9. Kusaka G, Ishikawa M, Nanda A, Granger DN and Zhang JH: Signaling pathways for early brain injury after subarachnoid hemorrhage. J Cereb Blood Flow Metab 24: 916-925, 2004.

10. Endo H, Nito C, Kamada H, Yu F and Chan PH: Akt/GSK3beta survival signaling is involved in acute brain injury after subarachnoid hemorrhage in rats. Stroke 37: 2140-2146, 2006.

11. Xu Q and Reed JC: Bax inhibitor-1, a mammalian apoptosis suppressor identified by functional screening in yeast. Mol Cell 1: 337-346, 1998

12. Chae HJ, Kim HR, Xu C, Bailly-Maitre B, Krajewska M, Krajewski S, Banares S, Cui J, Digicaylioglu M, Ke N, et al: BI-1 regulates an apoptosis pathway linked to endoplasmic reticulum stress. Mol Cell 15: 355-366, 2004.

13. Bredesen DE, Rao RV and Mehlen P: Cell death in the nervous system. Nature 443: 796-802, 2006.

14. Kim I, Xu W and Reed JC: Cell death and endoplasmic reticulum stress: Disease relevance and therapeutic opportunities. Nat Rev Drug Discov 7: 1013-1030, 2008.

15. Patil $\mathrm{C}$ and Walter P: Intracellular signaling from the endoplasmic reticulum to the nucleus: The unfolded protein response in yeast and mammals. Curr Opin Cell Biol 13: 349-355, 2001.

16. Hetz C, Bernasconi P, Fisher J, Lee AH, Bassik MC, Antonsson B, Brandt GS, Iwakoshi NN, Schinzel A, Glimcher LH and Korsmeyer SJ: Proapoptotic BAX and BAK modulate the unfolded protein response by a direct interaction with IRElalpha. Science 312: 572-576, 2006

17. Szegezdi E, Logue SE, Gorman AM and Samali A: Mediators of endoplasmic reticulum stress-induced apoptosis. EMBO Rep 7: 880-885, 2006.

18. Nishitoh H, Matsuzawa A, Tobiume K, Saegusa K, Takeda K, Inoue K, Hori S, Kakizuka A and Ichijo H: ASK1 is essential for endoplasmic reticulum stress-induced neuronal cell death triggered by expanded polyglutamine repeats. Genes Dev 16: 1345-1355, 2002.

19. Lei K and Davis RJ: JNK phosphorylation of Bim-related members of the Bcl2 family induces Bax-dependent apoptosis. Proc Natl Acad Sci USA 100: 2432-2437, 2003.

20. Krajewska M, Xu L, Xu W, Krajewski S, Kress CL, Cui J, Yang L, Irie F, Yamaguchi Y, Lipton SA and Reed JC: Endoplasmic reticulum protein BI-1 modulates unfolded protein response signaling and protects against stroke and traumatic brain injury. Brain Res 1370: 227-237, 2011.

21. Bailly-Maitre B, Fondevila C, Kaldas F, Droin N, Luciano F, Ricci JE, Croxton R, Krajewska M, Zapata JM, Kupiec-Weglinski JW, et al: Cytoprotective gene bi-1 is required for intrinsic protection from endoplasmic reticulum stress and ischemia-reperfusion injury. Proc Natl Acad Sci USA 103: 2809-2814, 2006.

22. Lu B, Li Y, Li H, Zhang Y, Xu J, Ren L, Fu S and Zhou Y: Bax inhibitor-1 is overexpressed in non-small cell lung cancer and promotes its progression and metastasis. Int J Clin Exp Pathol 8: $1411-1418,2015$.

23. Grzmil M, Thelen P, Hemmerlein B, Schweyer S, Voigt S, Mury D and Burfeind P: Bax inhibitor- 1 is overexpressed in prostate cancer and its specific down-regulation by RNA interference leads to cell death in human prostate carcinoma cells. Am J Pathol 163: 543-552, 2003. 
24. Bailly-Maitre B, Bard-Chapeau E, Luciano F, Droin N, Bruey JM, Faustin B, Kress C, Zapata JM and Reed JC: Mice lacking bi-1 gene show accelerated liver regeneration. Cancer Res 67: 1442-1450, 2007.

25. Bailly-Maitre B, Belgardt BF, Jordan SD, Coornaert B, von Freyend MJ, Kleinridders A, Mauer J, Cuddy M, Kress CL, Willmes D, et al: Hepatic Bax inhibitor-1 inhibits IRElalpha and protects from obesity-associated insulin resistance and glucose intolerance. J Biol Chem 285: 6198-6207, 2010.

26. Jeon K, Lim H, Kim JH, Han D, Lee ER, Yang GM, Song MK, Kim JH and Cho SG: Bax inhibitor-1 enhances survival and neuronal differentiation of embryonic stem cells via differential regulation of mitogen-activated protein kinases activities. Biochim Biophys Acta 1823: 2190-2200, 2012.

27. Dohm CP, Siedenberg S, Liman J, Esposito A, Wouters FS Reed JC, Bähr M and Kermer P: Bax inhibitor-1 protects neurons from oxygen-glucose deprivation. J Mol Neurosci 29: 1-8, 2006.

28. Prunell GF, Mathiesen T and Svendgaard NA: A new experimental model in rats for study of the pathophysiology of subarachnoid hemorrhage. Neuroreport 13: 2553-2556, 2002.

29. Sugawara T, Ayer R, Jadhav V and Zhang JH: A new grading system evaluating bleeding scale in filament perforation subarachnoid hemorrhage rat model. J Neurosci Methods 167: 327-334, 2008.

30. Livak KJ and Schmittgen TD: Analysis of relative gene expression data using real-time quantitative PCR and the 2(-Delta Delta C(T)) method. Methods 25: 402-408, 2001.

31. Alafuzoff I, Adolfsson R, Bucht G and Winblad B: Albumin and immunoglobulin in plasma and cerebrospinal fluid, and blood-cerebrospinal fluid barrier function in patients with dementia of Alzheimer type and multi-infarct dementia. J Neurol Sci 60: 465-472, 1983.

32. Sorjonen DC: Total protein, albumin quota, and electrophoretic patterns in cerebrospinal fluid of dogs with central nervous system disorders. Am J Vet Res 48: 301-305, 1987.

33. Kumar A, Mittal R, Khanna HD and Basu S: Free radical injury and blood-brain barrier permeability in hypoxic-ischemic encephalopathy. Pediatrics 122: e722-e727, 2008.

34. Schmidt-Kastner R, Szymas J and Hossmann KA: Immunohistochemical study of glial reaction and serum-protein extravasation in relation to neuronal damage in rat hippocampus after ischemia. Neuroscience 38: 527-540, 1990.

35. Suzuki H: What is early brain injury? Transl Stroke Res 6: 1-3, 2015.

36. Sehba FA, Hou J, Pluta RM and Zhang JH: The importance of early brain injury after subarachnoid hemorrhage. Prog Neurobiol 97: 14-37, 2012.
37. Hosaka $\mathrm{K}$ and Hoh BL: Inflammation and cerebral aneurysms. Transl Stroke Res 5: 190-198, 2014.

38. Chen S, Yang Q, Chen G and Zhang JH: An update on inflammation in the acute phase of intracerebral hemorrhage. Transl Stroke Res 6: 4-8, 2015

39. Sabri M, Kawashima A, Ai J and Macdonald RL: Neuronal and astrocytic apoptosis after subarachnoid hemorrhage: A possible cause for poor prognosis. Brain Res 1238: 163-171, 2008.

40. Matz PG, Fujimura M and Chan PH: Subarachnoid hemolysate produces DNA fragmentation in a pattern similar to apoptosis in mouse brain. Brain Res 858: 312-319, 2000.

41. Lindholm D, Wootz H and Korhonen L: ER stress and neurodegenerative diseases. Cell Death Differ 13: 385-392, 2006.

42. He Z, Ostrowski RP, Sun X, Ma Q, Huang B, Zhan Y and Zhang JH: CHOP silencing reduces acute brain injury in the rat model of subarachnoid hemorrhage. Stroke 43: 484-490, 2012.

43. Roussel BD, Kruppa AJ, Miranda E, Crowther DC, Lomas DA and Marciniak SJ: Endoplasmic reticulum dysfunction in neurological disease. Lancet Neurol 12: 105-118, 2013.

44. Placido AI, Pereira CM, Duarte AI, Candeias E, Correia SC, Carvalho C, Cardoso S, Oliveira CR and Moreira PI: Modulation of endoplasmic reticulum stress: An opportunity to prevent neurodegeneration? CNS Neurol Disord Drug Targets 14: 518-533, 2015.

45. Stefani IC, Wright D, Polizzi KM and Kontoravdi C: The role of ER stress-induced apoptosis in neurodegeneration. Curr Alzheimer Res 9: 373-387, 2012.

46. McManusMJ,Murphy MPandFranklinJL: Mitochondria-derived reactive oxygen species mediate caspase-dependent and-independent neuronal deaths. Mol Cell Neurosci 63: 13-23, 2014.

47. Winklhofer KF and Haass C: Mitochondrial dysfunction in Parkinson's disease. Biochim Biophys Acta 1802: 29-44, 2010.

48. Itoh K, Nakamura K, Iijima M and Sesaki H: Mitochondrial dynamics in neurodegeneration. Trends Cell Biol 23: 64-71, 2013.

49. Chen J, Wang L, Wu C, Hu Q, Gu C, Yan F, Li J, Yan W and Chen G: Melatonin-enhanced autophagy protects against neural apoptosis via a mitochondrial pathway in early brain injury following a subarachnoid hemorrhage. J Pineal Res 56: 12-19, 2014.

50. Liang Y, Che X, Zhao Q, Darwazeh R, Zhang H, Jiang D, Zhao J, Xiang X, Qin W, Liu L and He Z: Thioredoxin-interacting protein mediates mitochondrion-dependent apoptosis in early brain injury after subarachnoid hemorrhage. Mol Cell Biochem, 2018. 